\title{
Analysis of $\beta$-catenin association with obesity in African Americans with premalignant and malignant colorectal lesions
}

Babak Shokrani ${ }^{1 *} \mathbb{D}$, Hassan Brim ${ }^{1}$, Tahmineh Hydari ${ }^{1}$, Ali Afsari ${ }^{1}$, Edward Lee ${ }^{1}$, Mehdi Nouraie ${ }^{2}$, Zaki Sherif ${ }^{1}$ and Hassan Ashktorab ${ }^{1 *}$

\begin{abstract}
Background: African Americans (AA) are at high risk for Colorectal Cancer (CRC). Studies report a 30-60\% increase in CRC risk with physical inactivity, obesity and metabolic syndrome. Activation of the WNT/ $\beta$-catenin (CTNNB1) signaling pathway plays a critical role in colorectal carcinogenesis. Accumulating evidence also indicates a role of WNT-CTNNB1 signaling in obesity and metabolic diseases.

Aim: To examine the association between obesity, $\beta$-Catenin expression and colonic lesions in African Americans.

Methods: We reviewed the pathology records of 152 colorectal specimens from 2010 to 2012 (46 CRCs, 74 advanced adenomas and 32 normal colon tissues). Tissue Microarrays (TMA) were constructed from these samples. Immunohistochemistry (IHC) for CTNNB1 ( $\beta$-Catenin; clone $\beta$-Catenin-1) was performed on the constructed TMAs. The IHC results were evaluated by 2 pathologists and the nuclear intensity staining was scored from 0 to 4 . BMI, sex, age, location of the lesion and other demographic data were obtained.

Results: Positive nuclear staining in normal, advanced adenoma and CRC was 0, 24 and 41\%, respectively ( $P<$ 0.001). CRC was asso ciated with positive status for nuclear CTNNB1 intensity (adjusted OR: $3.40,95 \% \mathrm{Cl}=1.42-8.15$, $P=0.006$ for positive nuclear staining) compared to non-CRC samples (Normal or advanced adenoma). Nuclear staining percentage has a fair diagnostic ability for CRC with an AUC of $0.63(95 \% \mathrm{Cl}=0.55-0.71)$.

Overweight/obese patients (BMI > 25) did not show a significant difference in $(p=0.3)$ nuclear CTNNB1 staining (17\% positive in normal weight vs. $27 \%$ positive in overweight/obese). The association between nuclear intensity and CRC was not different between normal and overweight patients ( $P$ for interaction $=0.6$ ). The positive nuclear CTNNB1 status in CRC stage III and IV (35\% of all CRC) was not different from stage I and II (50\% vs. 36\%, respectively, $P=0.4)$.
\end{abstract}

\footnotetext{
* Correspondence: b_shokrani@howard.edu; hashktorab@howard.edu 'Department of Medicine, Department of Pathology and Cancer Center, Howard University College of Medicine, 2041 Georgia Avenue, N.W, Washington, D.C 20060, USA

Full list of author information is available at the end of the article
}

(c) The Author(s). 2020 Open Access This article is licensed under a Creative Commons Attribution 4.0 International License, which permits use, sharing, adaptation, distribution and reproduction in any medium or format, as long as you give appropriate credit to the original author(s) and the source, provide a link to the Creative Commons licence, and indicate if changes were made. The images or other third party material in this article are included in the article's Creative Commons licence, unless indicated otherwise in a credit line to the material. If material is not included in the article's Creative Commons licence and your intended use is not permitted by statutory regulation or exceeds the permitted use, you will need to obtain permission directly from the copyright holder. To view a copy of this licence, visit http://creativecommons.org/licenses/by/4.0/ The Creative Commons Public Domain Dedication waiver (http://creativecommons.org/publicdomain/zero/1.0/) applies to the data made available in this article, unless otherwise stated in a credit line to the data. 
(Continued from previous page)

Conclusion: In our study, advanced adenoma and CRC were associated with activation of $\beta$-catenin in physically fit, overweight and obese patients. Thus, obesity and WNT/ $\beta$-Catenin pathway seem to be independent in African American patients. WNT/ $\beta$-Catenin signaling pathway has a potential to be used as an effector in colon carcinogenic transformation. Whether or not BMl is a modifier of this pathway needs to be investigated further.

Keywords: $\beta$-Catenin, Colorectal cancer, Advanced adenoma, African Americans

\section{Background}

Colorectal cancer (CRC) is one of the most common cancers in the industrialized world [1]. Lifestyle and epidemiological factors associated with an increased risk of CRC include physical inactivity, obesity and metabolic syndrome [2]. In the United States, approximately twothirds of the adult population are overweight or obese, which represents a putative risk factor for multiple target organ malignancies, including CRC [3].

There is evidence to suggest that excess adiposity is associated with up to $60 \%$ greater risk of CRC compared with normal weight individuals [4], and that physical activity may decrease colorectal cancer risk [5]. Although excessive accumulation of white adipose tissue (WAT) is the key feature of adiposity, obesity is clinically defined by a BMI over $30 \mathrm{~kg} / \mathrm{m}^{2}$, which does not take fat content into account. It is also known that most CRCs arise from a genetic and morphological adenoma to carcinoma transition. Also, it is widely accepted that both CRCs and colorectal adenomas (CRAs) share similar etiological causes which explains why CRAs, which are amongst the most frequent pathological findings in all CRC screening participants, are present in more than $30 \%$ of general asymptomatic populations [6]. Consequently, risk algorithms have been applied to use BMI as a predictor variable to stratify individuals according to their risk of colorectal neoplasia [7]. However, the underlying mechanisms that might explain the association and the magnitude of the connection between excess body weight and CRC remain unclear.

In the obesity-cancer relationship, multiple biological processes including insulin, insulin-like growth factor (IGF)-1, insulin resistance, sexual hormones (estrogens) and pro-inflammatory cytokines (TNF- $\alpha$, IL- 6 and CRP) actively participate [8]. All these elements create a favorable environment for carcinogenesis and a decrease in apoptosis.

As a separate molecular pathway, activation of the WNT signaling pathway plays a critical role in colorectal carcinogenesis [9]. WNT ligands are a family of proteins that are important for normal cell development. $\beta$ Catenin (CTNNB1) is a major mediator of the WNT pathway, that is traditionally classified into canonical $(\beta-$ Catenin-dependent) and non-canonical $(\beta$-Catenin-independent). WNT canonical pathway utilizes a group of cell surface receptors called frizzled (FRZ) to activate several pathways, the most important one involving $\beta$ Catenin and APC [10]. In the absence of WNT signaling, APC causes degradation of $\beta$-Catenin, preventing its accumulation in the cytoplasm by forming a complex with $\beta$-Catenin, which leads to the phosphorylation and eventually destruction of $\beta$-Catenin by the proteasome. Signaling by WNT blocks this process, allowing $\beta$-Catenin to migrate from the cytoplasm to the nucleus. Once in the nucleus, $\beta$-Catenin up-regulates $c-M Y C$, cyclin $D 1$, and other genes which increase cellular proliferation [11]. Therefore, continuous WNT signaling can be seen in cells with loss of APC [12].

Metabolic syndrome-associated conditions such as obesity and type II diabetes are influenced by genetic and functional variations in the WNT signaling pathway [13]. WNT signaling, when activated, represses the terminal differentiation during adipogenesis whereby preadipocytes take on the characteristics of mature adipocytes. A cascade of transcriptional events like the induction of $\beta$-Catenin ensues, which in turn induces enhancer binding protein- $\alpha$ (CEBPA) and peroxisome proliferator-activated receptor- $\gamma$ (PPARG) [14]. The excessive accumulation of WAT features adiposity but obesity does not take fat content into account [15]. Recently, genetic factors linked to fat mass and adiposity were reported to be associated with increased obesity risk [16]. In young obese individuals, whole-exome sequencing revealed rare gain-of-function mutations in CTNNB1/ $\beta$-catenin [16]. The $\beta$-Catenin-regulated transcription of an adipocyte-derived chemokine called serum amyloid A3 (Saa3) leads to the formation of a $\beta$ Catenin-TCF complex in mature adipocytes that promotes the proliferation of pre-adipocytes in WAT and thereby increases obesity and the risk for metabolic syndrome. Other data also suggest that obesity and lack of physical activity are associated with a higher risk for colorectal cancer $[17,18]$. These findings have important implications especially in the obese and physically inactive African American population that may have underlying predisposing mutations to colorectal cancer [19].

The aim of this study is to assess the $\beta$-Catenin expression profile in colorectal pre-malignant and malignant lesions in correlation with obesity as determined by 
body mass index (BMI) or waist circumference (WC) in African American population.

\section{Methods}

\section{Patients and clinical data}

Colorectal tissue samples submitted to the Surgical Pathology Laboratory at Howard University Hospital from January 1, 2010 to December 31, 2012 were retrieved from the pathology archive system (PowerPath ${ }^{\mathrm{Tm}}$ ). A total of 152 samples were included in the study consisting of tissue samples from CRC $(n=46)$, advanced adenoma $(n=74)$ and normal colon $(n=32)$. Patients' data included age, sex, height, weight and waist circumference. Body mass index (BMI) was calculated in the study (Table 1). The protocol of this study was approved by the Howard University Institutional Review Board (IRB).

\section{Tissue microarray (TMA) construction}

Hematoxylin-Eosin stained slides (H\&E slides) were made from paraffin-embedded blocks. The H\&E slides were reviewed by two pathologists to confirm the pathological diagnosis and to mark areas of interest. Multiple areas from more than one block were marked to ensure a good representability of the sample on the TMA. Five TMA paraffin blocks, each containing 75 cores of $1 \mathrm{~mm}$ in diameter each and $0.5 \mathrm{~mm}$ distance from each other, were constructed. Tissue-specific and organ system controls were included in each TMA.

\section{Immunohistochemical (IHC) analysis of CTNNB1 ( $\beta$ - catenin)}

The constructed TMAs were stained for $\beta$-Catenin. The immunostaining was carried out as follows. Dako Monoclonal Mouse Anti-Human Beta-Catenin ( $\beta$-CateninC- 1 ) intended for laboratory application to identify qualitatively by light microscopy $\beta$-catenin positive cells in normal and neoplastic tissues, was used at a dilution of 1 : 200, using the EnVision+, DAB (code K4006) detection system. The deparaffinized TMAs were treated prior to the IHC staining procedure. Target retrieval involved immersion of tissue sections in a pre-heated buffer solution and maintaining heat in a water bath $\left(95-99^{\circ} \mathrm{C}\right)$. For greater adherence of tissue sections to glass slides, silanized slides (Dako code S3003) were used. Target
Retrieval Solution (code S1700) or 10x Concentrate (code S1699) using a 20-min heating protocol was used. The cellular staining pattern of anti- $\beta$-Catenin is mainly membranous, especially at the cell-cell boundaries. Positive nuclear staining and diffuse cytoplasmic staining are also reported in cancer cells (Fig. 1).

\section{Evaluation and assessment of the $\beta$-catenin expression}

Two pathologists interpreted the IHC slides. $\beta$-Catenin expression status was assessed based on the pattern of staining (nuclear, cytoplasmic, and membranous), intensity (0 to $4+$ ) and percentage of staining (0 to 100\%). The staining would be considered negative if there was weak or no nuclear expression, or positive if there was moderate or strong nuclear expression.

\section{Statistical analysis}

Distribution of continuous and categorical variables were tested by Kruskal-Wallis and Chi-square test between different groups, respectively. We used logistic regression analysis to test association between the staining and risk of CRC, after adjusting for age and gender. Area under the curve (AUC) was calculated for variables with significant association with CRC using Receiver Operative Characteristics curve. All statistical analyses were performed by STATA 13.0 (STATACorp., College Station, TX).

\section{Results}

Epidemiological characteristics and BMI in normal, advanced adenoma and CRC

The BMI was calculated for individual patients and normal subjects as represented in Table 1. CRC patients were older $(p=0.004)$, while our healthy normal population was mostly overweight. Higher BMI was more closely associated with advanced adenoma and CRC. However, the differences were not significant (Table 1).

\section{Advanced adenomas and CRCs were associated with positive nuclear CTNNB1}

We assessed whether alterations in WNT-CTNNB1 $(\beta-$ Catenin) signaling plays any role colon carcinogenesis. Positive $\beta$-Catenin nuclear stains were seen in normal, advanced adenomas and CRCs were 0,24 and $41 \%$, respectively $(P<0.001$; Table 2$)$. Based on the designation

Table 1 Epidemiological characteristics and BMI in normal, advanced adenoma and CRC patients

\begin{tabular}{lllll}
\hline & Normal & Advanced Adenoma & CRC \\
& $N=32$ & $N=74$ & $N=46$ \\
\hline Age, median (IQR) & $63(55-75)$ & $61(56-64)$ & $68(53-76)$ & \\
Male, n (\%) & $15(47)$ & $24(57 \%)$ & $24(48)$ & 0.004 \\
BMI (kg/m2), median (IQR) & $26.1(22.6-29.9)$ & $29.5(26.3-35.9)$ & $29.3(20.8-35.3)$ & 0.8 \\
Overweight, n (\%) & $15(60)$ & $32(78)$ & $20(69)$ & 0.3 \\
\hline
\end{tabular}




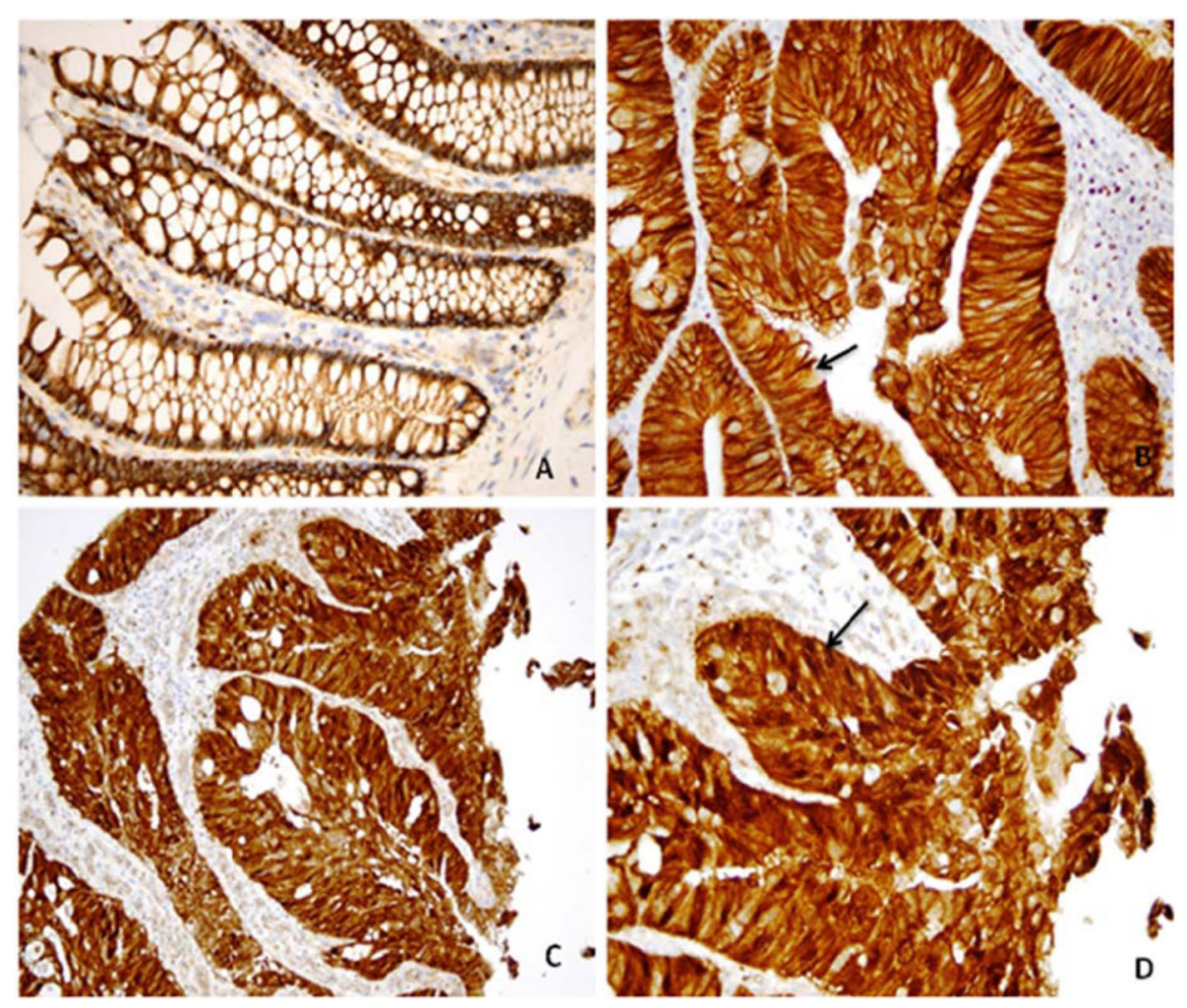

Fig. 1 Immunostain for $\beta$-catenin in three individuals; normal $(\mathbf{a}, \times 400)$, advanced adenoma $(\mathbf{b}, \times 400)$ and cancer $(\mathbf{c} \& \mathbf{d}, \times 200$ and $\times 400$ respectively) showing membranous staining in the normal, cytoplasmic and membranous staining in adenoma with no evidence of nuclear expression (arrow showing lack of nuclear staining) and nuclear and cytoplasmic staining in cancer (arrow showing nuclear staining)

of " $\mathrm{N}$ intensity + ", which is associated with higher risk of cancer, CRCs were associated with positive status for nuclear CTNNB1 intensity (age, gender adjusted OR: $3.40,95 \% \mathrm{CI}=1.42-8.15, P=0.006$ for positive nuclear staining) compared to non-CRC samples (Normal or advanced adenoma) (Fig. 1). Nuclear staining percentage has also a fair diagnostic ability for CRC with an AUC of $0.63(95 \% \mathrm{CI}=0.55-0.71$; Table 2, Fig. 2).

\section{Overweight and obese patients show a trend with} positive nuclear CTNNB1 expression

Positive nuclear CTNNB1 staining was $17 \%$ in normal weight and $27 \%$ in overweight/obese (BMI > 25) patients.
This difference pointed to trend that was not statistically significant.

Association between nuclear intensity and CRC in normal and overweight patients

The association between nuclear intensity and CRC was not statistically significant different between normal weight and overweight patients ( $P$ for interaction $=0.6$; Tables 3 and 4). The positive nuclear CTNNB1 status in CRC stage III and IV (35\% of all CRC) was not different from stage I and II (50\% vs. $36 \%$, respectively, $P=0.4$ ).

Table 2 $\beta$-Catenin nuclear and cytoplasmic expression tabulated as intensity and percentage in normal, advanced adenoma, and CRC

\begin{tabular}{lllllll}
\hline & Normal & Advanced Adenoma $N=74$ & CRC & Overall $P$ value & $P$ value for Advanced Adenoma vs. Normal & $P$ value for CRC vs. other \\
& $N=32$ & & $N=46$ & & 0.07 \\
$\mathbf{C} \%$ & $100(10-100)$ & $100(80-100)$ & $100(100-100)$ & 0.004 & 0.3 & 0.012 \\
N\% & $0(0-0)$ & $0(0-0)$ & $0(0-10)$ & 0.009 & 0.006 & 0.1 \\
C Intensity + & $26(81 \%)$ & $74(100 \%)$ & $46(100 \%)$ & $<0.001$ & $<0.001$ & 0.001 \\
N Intensity + & 0 & $18(24 \%)$ & $19(41 \%)$ & $<0.001$ & 0.002 & \\
\hline
\end{tabular}

C Cytoplasmic, $N$ Nuclear

$\mathrm{C}$ Intensity+ and N Intensity+ mean Intensity 1 and above 


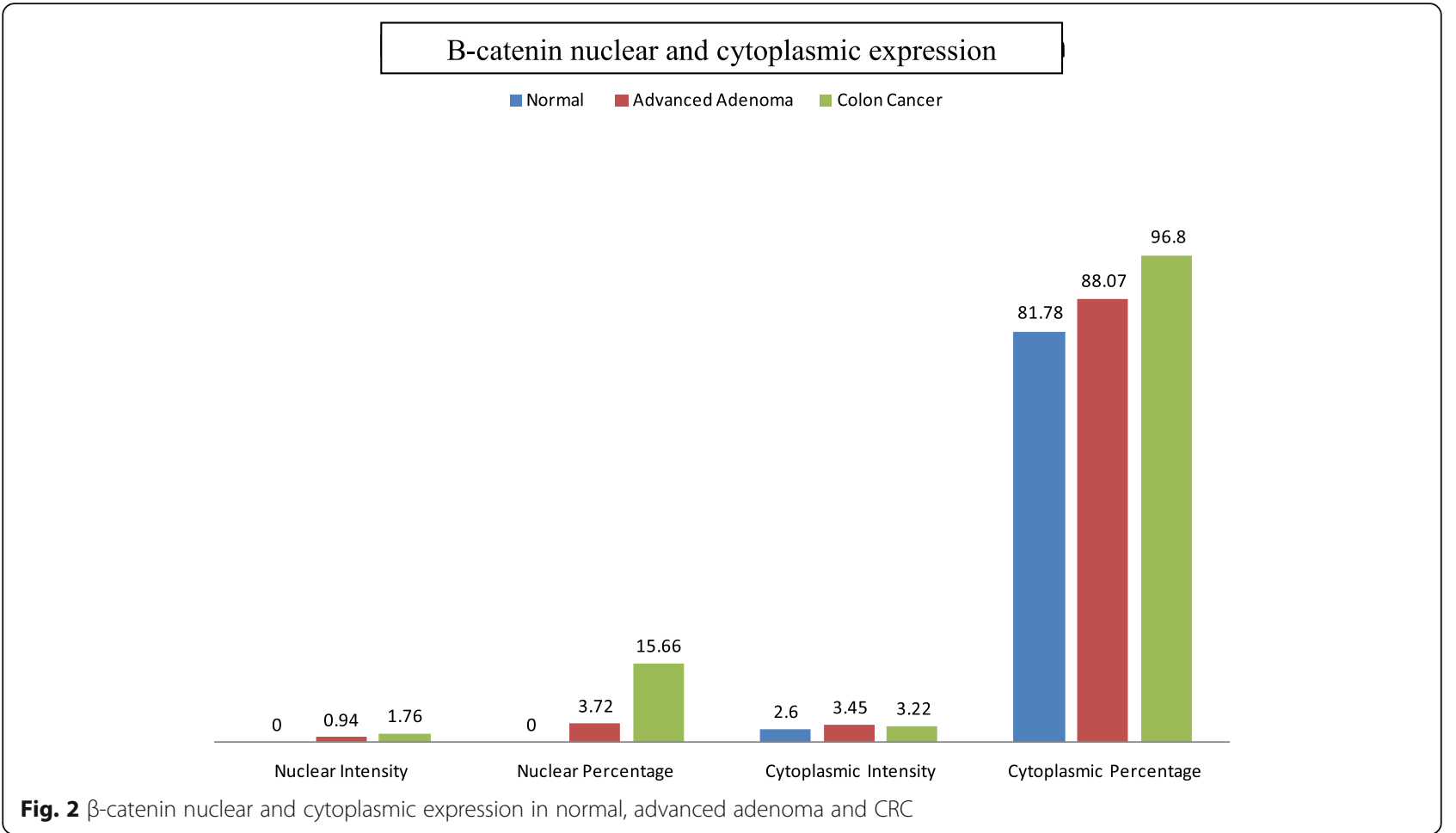

\section{Discussion}

One of the important risk factors in colorectal cancer is obesity $[3,4]$. $\beta$-Catenin is an E-cadherin binding protein that mediates cell-cell adhesion [20] and plays a role in the canonical WNT signaling pathway that controls the coordinated expansion and differentiation of the intestinal crypt stem cells [21]. Degradation of $\beta$-Catenin by phosphorylation followed by alteration of destruction complex (APC, GSK-3 $\beta$ and AXIN) results in inactivation if WNT pathway [22]. In our study, we found that was associated with an increased adjusted OR of 3.40 $(95 \% \mathrm{CI}=1.42-8.15, P=0.006$ for positive nuclear staining) compared to non-CRC samples (Normal or advanced adenoma).

The gatekeeper gene APC is a negative regulator of $\beta$ Catenin and is mutated in approximately $80 \%$ of sporadic and hereditary colon cancers [23]. There are several mutations that can cause an accumulation of $\beta$-Catenin in tumor cells such as mutations of the APC gene, point mutations in GSK-3 $\beta$ or mutations in $\beta$-Catenin gene itself [23-25].
Our positive nuclear staining in CRC (41\%) and its association with the positive status for nuclear CTNNB1 intensity compared to non-CRC samples are in contrast to a study by Brabletz et al. [26], which showed that $\beta$ Catenin is localized in the cytoplasm and membrane of the tumor cells whereas in our study it was mainly concentrated in the cytoplasm and the nucleus. They also mentioned that there was positive nuclear staining at the invasive front as $\beta$-Catenin is involved in tumor progression. Such is not the case in our study, indeed even when considering nuclear staining in our specimens, there was no statistically significant differences between stage III/IV cases' staining versus stages I/II CRC cases levels of staining. The fact that $\beta$-Catenin is expressed early in the African American specimens analyzed here might partially explain the aggressive nature of CRC in this population. In addition, we showed that there is uniform membranous staining in normal and increasing cytoplasmic and nuclear staining in advanced adenomas and CRCs. This confirms that the decrease in membranous staining begins with dysplastic changes leading to a

Table 3 Association of BMI with $\beta$-Catenin nuclear intensity in advanced adenoma cases

\begin{tabular}{llll}
\hline \multicolumn{1}{l}{ Advanced adenoma with $\beta$-Catenin expression $4+(n=9)$ in intensity and no nuclear intensity $(n=28)}$. \\
\hline & $\begin{array}{l}\text { Nuclear intensity (negative) } \\
n=28\end{array}$ & $\begin{array}{l}\text { Nuclear intensity }(4+) \\
n=9\end{array}$ & $P$ value \\
\hline BMl, median (interquartile) & $29.2(24.3-34.9)$ & $33.2(26.6-37.0)$ & 0.3 \\
Overweight, $\mathrm{n}(\%)$ & $20(71 \%)$ & $8(89 \%)$ & 0.3 \\
\hline
\end{tabular}


Table 4 Association of BMI with $\beta$-Catenin nuclear intensity in CRC cases

\begin{tabular}{llll}
\hline CRC with $\beta$-Catenin expression with high nuclear intensity (4+) and without (negative). & \\
\hline & $\begin{array}{l}\text { Nuclear intensity (negative) } \\
n=14\end{array}$ & $\begin{array}{l}\text { Nuclear intensity (4+) } \\
n=12\end{array}$ \\
\hline BMI, median (interquartile) & $29.3(18.2-40.0)$ & $30.1(22.8-35.3)$ \\
Overweight, $n(\%)$ & $8(57)$ & $9(75)$ & 0.8 \\
\hline
\end{tabular}

progressive disappearance at the membrane level in CRCs.

As we mentioned above, a major risk factor for CRC is obesity, which continues to expand as a pandemic worldwide [27]. The American Cancer Society Cancer Prevention Study II, states that there is an increased incidence of CRC, esophageal adenocarcinoma and other cancers with obesity [28]. In our study, we showed that $78 \%$ of advanced adenoma patients and $69 \%$ of CRC patients were overweight with $\mathrm{BMI}>25$. In comparison to advanced adenoma, the percentage was lower in cancer; perhaps due to the late stage of cancer and weight loss in the interim (Table 1). There are several mechanisms by which obesity is believed to promote $\mathrm{CRC}$, this includes increase in leptin levels that cause an increase in growth and proliferation of colon cancer cells [29], altered adipokine levels, altered gut microbiome apart from increased steroid hormones and growth factors [30]. Insulin is however the established biochemical link and the main pathway involved is PIK3/AKT/mTOR pathway. Elevated IGF-1 and insulin act through the insulin receptors and phosphotidylinositide-3 kinase [31].

In addition to the above findings, we also found that overweight and obese patients $(\mathrm{BMI}>25)$ did not show a significantly increased expression $(p=0.3)$ of nuclear CTNNB1 (17\% positive in normal weight vs. $27 \%$ positive in overweight/obese). Morikawa et al. found that in obese patients, nuclear CTNNB1 positivity was associated with significantly better cancer-specific survival suggesting that WNT signaling acts as a switch and when it is on, adipogenesis is repressed. Kennell et al. demonstrated that activated Frz1 (frizzled) promotes $\beta$ Catenin stability, inhibits apoptosis, and adipogenesis. Ross, et al. also showed that Wnt signaling acts as a molecular switch that controls adipogenesis. Upregulation of Wnt signaling maintains preadipocytes in an undifferentiated state and when Wnt signaling is prevented they differentiate into adipocytes [17, 32, 33].

Although in our study there was no association between nuclear intensity and CRC between normal and overweight patients ( $\mathrm{P}$ for interaction $=0.6$ ), there is accumulating evidence to show that the state of chronic inflammation incited by obesity might play a role in promoting colorectal carcinogenesis $[8,34]$. Of the many markers, TNF- $\alpha$ is important $[35,36]$, as it activates WNT signaling through the induction of GSK-3 $\beta$ phosphorylation, resulting in increased nuclear localization of $\beta$-Catenin [37]. In addition to TNF- $\alpha$, other humoral agents associated with obesity might also be contributing to the activation of WNT signaling like IL-1 $\beta$ and adiponectin, which is decreased in the obese state and is not an inflammatory cytokine that can modulate GSK3 $\beta / \beta$ Catenin signaling pathway [38]. Although multiple mechanisms may be operating in parallel and contributing to the pro-tumorigenic milieu, Wnt is a pivotal tumorigenic pathway [39], aberrations of which is

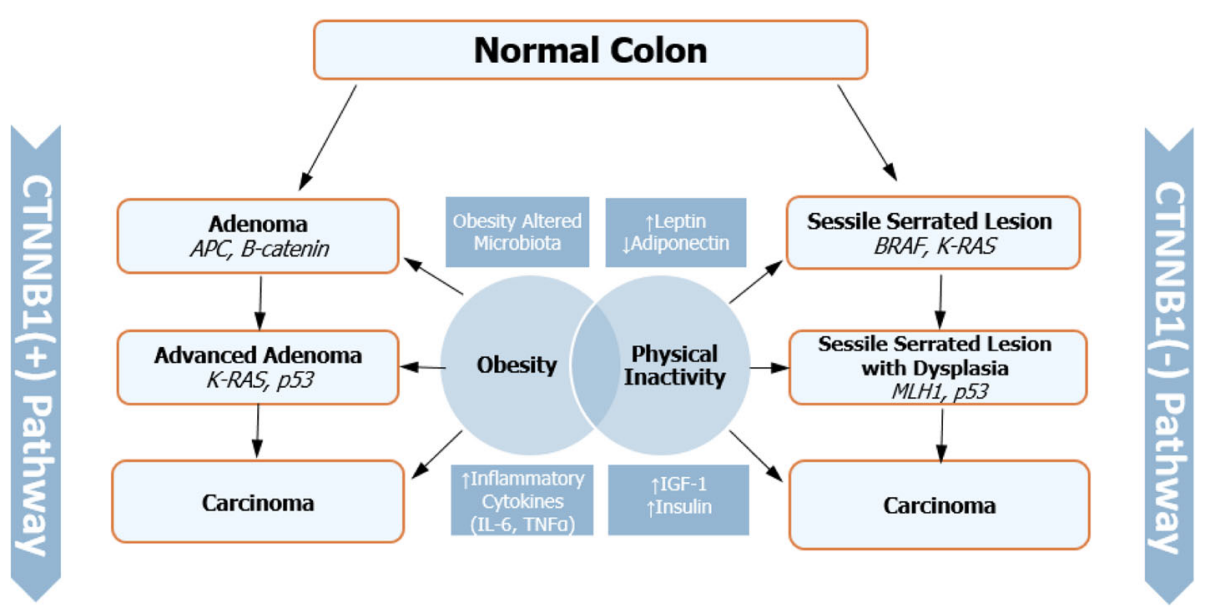

Fig. 3 The putative relationship between obesity and colorectal cancer evolution pathways by cellular CTNNB1 status, based on the data by the current study. Our study suggests that there is no association between obesity and CTNNB1 expression 
important in the evolution of most sporadic CRC. In summary, there is positive nuclear staining in CRCs (41\%), which was associated with the positive status for nuclear CTNNB1 intensity (adjusted OR: 3.40, 95\%CI = $1.42-8.15 \%, P=0.006$ for positive nuclear staining) compared to non-CRC samples (Normal or advanced adenoma). This shows that advanced adenomas and CRCs were associated with activation of $\beta$-Catenin in physically fit, overweight and obese patients (Fig. 3).

\section{Conclusion}

Advanced adenoma and CRC were associated with activation of $\beta$-Catenin in physically fit, overweight and obese patients. Thus, participation of obesity and WNT pathway seem to be independent CRC factors in African American patients. Inflammation-driven activation of WNT signaling as a potential pathway linking obesity to the development of CRC needs to be investigated further in the African American population. This might provide insights into the identification of new therapeutic targets to reduce the burden of obesity-associated CRC.

\section{Abbreviations}

CRC: Colorectal cancer; WAT: White adipose tissue; AA: African Americans

\section{Acknowledgements}

Not applicable.

\section{Authors' contributions}

Conceived and designed experiments: BS, HA; performed experiments: BS, EL, HA, HB; analyzed data: HA, HB, MN, TH, AA, and ZS; contributed reagents/ materials/analysis tools: $\mathrm{ZS}, \mathrm{HA}, \mathrm{HB}, \mathrm{BS}$, and EL wrote and edited manuscript: $B S$, and $H A$; provided statistical analysis: MN. All authors have read and approved the manuscript.

\section{Funding}

This project was supported in part by grant from the National Institute on Minority Health and Health Disparities of the National Institutes of Health under award numbers.

G12MD007597. The funder had no role in designing or execution of this study.

\section{Availability of data and materials}

All data generated or analyzed during this study are included in this published article.

\section{Ethics approval and consent to participate}

This retrospective and chart review study was conducted according to the World Medical Association Declaration of Helsinki and was approved by the Internal Review Board of Howard University. Since the chart review was done through un-identifiable approach no consent form needed for this study.

\section{Consent for publication}

Not applicable.

\section{Competing interests}

The authors declare that they have no competing interests related to this manuscript.

\section{Author details}

'Department of Medicine, Department of Pathology and Cancer Center, Howard University College of Medicine, 2041 Georgia Avenue, N.W, Washington, D.C 20060, USA. ${ }^{2}$ Division of Pulmonary, Allergy and Critical Care Medicine, University of Pittsburg, Pittsburg, PA, USA.
Received: 22 April 2020 Accepted: 7 August 2020

Published online: 18 August 2020

\section{References}

1. Research, I.A.f.C.o. Estimated cancer incidence, mortality and prevalence worlwide in 2012. Lyon: GLOBOCAN; 2012

2. Haggar FA, Boushey RP. Colorectal cancer epidemiology: incidence, mortality, survival, and risk factors. Clin Colon Rectal Surg. 2009;22(4):191-7.

3. Oxentenko AS, et al. Body size and incident colorectal cancer: a prospective study of older women. Cancer Prev Res (Phila). 2010;3(12):1608-20.

4. Ma Y, et al. Obesity and risk of colorectal cancer: a systematic review of prospective studies. PLoS One. 2013;8(1):e53916.

5. Slattery ML. Physical activity and colorectal cancer. Sports Med. 2004:34(4): 239-52.

6. Wong MC, Lam TY, Tsoi KK, Hirai HW, Chan VC, Ching JY, Chan FK, Sung JJ. A validated tool to predict colorectal neoplasia and inform screening choice for asymptomatic subjects. Gut. 2014;63:1130-6.

7. Sung JJY, Wong MCS, Lam TYT, Tsoi KKF, Chan VCW, Cheung W, Ching JYL. A modified colorectal screening score for prediction of advanced neoplasia: a prospective study of 5744 subjects. J.Gastroenterol.Hepatol. 2018;33:18794.

8. Liu Z, et al. Diet-induced obesity elevates colonic TNF-alpha in mice and is accompanied by an activation of Wnt signaling: a mechanism for obesityassociated colorectal cancer. J Nutr Biochem. 2012;23(10):1207-13.

9. Najdi R, Holcombe RF, Waterman ML. Wht signaling and colon carcinogenesis: beyond APC. J Carcinog. 2011;10:5.

10. MacDonald BT, Tamai K, He X. Wnt/beta-catenin signaling: components, mechanisms, and diseases. Dev Cell. 2009;17(1):9-26.

11. Denysenko T, et al. WNT/beta-catenin signaling pathway and downstream modulators in low- and high-grade Glioma. Cancer Genomics Proteomics. 2016:13(1):31-45

12. Willert K, Nusse R. Beta-catenin: a key mediator of Wnt signaling. Curr Opin Genet Dev. 1998:8(1):95-102.

13. Vella A, Camilleri M. Pharmacogenetics: potential role in the treatment of diabetes and obesity. Expert Opin Pharmacother. 2008:9(7):1109-19.

14. Christodoulides C, et al. Adipogenesis and WNT signalling. Trends Endocrinol Metab. 2009;20(1):16-24.

15. World Health Organization, 2017. [http://www.who.int/mediacentre/ factsheets/fs311/en/].

16. Chen M, Lu P, Ma Q, Cao Y, Chen N, Li W, Zhao S, Chen B, Shi J, Sun Y, Shen $H$, Sun L, Shen J, Liao Q, Zhang Y, Hong J, Gu W, Liu R, Ning G, Wang W, Wang J. CTNNB1/beta-catenin dysfunction contributes to adiposity by regulating the cross-talk of mature adipocytes and preadipocytes. Sci Adv. 2020;6:eaax9605

17. Morikawa T, Kuchiba A, Yamauchi M, Meyerhardt JA, Shima K, Nosho K, Chan AT, Giovannucci E, Fuchs CS, Ogino S. Association of CTNNB1 (betacatenin) alterations, body mass index, and physical activity with survival in patients with colorectal cancer. JAMA. 2011:305:1685-94.

18. Morikawa T, et al. Prospective analysis of body mass index, physical activity, and colorectal cancer risk associated with beta-catenin (CTNNB1) status. Cancer Res. 2013;73(5):1600-10.

19. Ashktorab H, Kupfer SS, Brim H, Carethers JM. Racial disparity in gastrointestinal cancer risk. Gastroenterology. 2017;153(4):910-23.

20. Kaler $P$, Augenlicht L, Klampfer L. Activating mutations in beta-catenin in colon cancer cells alter their interaction with macrophages; the role of snail. PLoS One. 2012;7(9):e45462.

21. Enzo MV, et al. The Wnt/beta-catenin pathway in human fibrotic-like diseases and its eligibility as a therapeutic target. Mol Cell Ther. 2015;3:1.

22. Stamos JL, Weis WI. The beta-catenin destruction complex. Cold Spring Harb Perspect Biol. 2013;5(1):a007898.

23. Chung GG, et al. Tissue microarray analysis of beta-catenin in colorectal cancer shows nuclear phospho-beta-catenin is associated with a better prognosis. Clin Cancer Res. 2001;7(12):4013-20.

24. Miyoshi $Y$, et al. Activation of the beta-catenin gene in primary hepatocellular carcinomas by somatic alterations involving exon 3. Cancer Res. 1998:58(12):2524-7.

25. Fukuchi T, et al. Beta-catenin mutation in carcinoma of the uterine endometrium. Cancer Res. 1998:58(16):3526-8.

26. Brabletz $\mathrm{T}$, et al. Variable beta-catenin expression in colorectal cancers indicates tumor progression driven by the tumor environment. Proc Natl Acad Sci U S A. 2001;98(18):10356-61. 
27. Berger NA. Obesity-associated gastrointestinal tract cancer: from beginning to end. Cancer. 2014;120(7):935-9.

28. Calle EE, et al. The American Cancer Society Cancer Prevention Study II Nutrition Cohort: rationale, study design, and baseline characteristics. Cancer. 2002;94(2):500-11.

29. Frezza EE, Wachtel MS, Chiriva-Internati M. Influence of obesity on the risk of developing colon cancer. Gut. 2006;55(2):285-91.

30. Berger NA. Obesity and cancer pathogenesis. Ann N Y Acad Sci. 2014;1311: $57-76$.

31. Guo S. Insulin signaling, resistance, and the metabolic syndrome: insights from mouse models into disease mechanisms. J Endocrinol. 2014:220(2):T1T23.

32. Ross SE, et al. Inhibition of adipogenesis by Wnt signaling. Science. 2000; 289(5481):950-3.

33. Kennell JA, MacDougald OA. Wnt signaling inhibits adipogenesis through beta-catenin-dependent and -independent mechanisms. J Biol Chem. 2005; 280(25):24004-10.

34. Liu Z, Yingka Y. Inflammation driven activation of Wnt pathway: a potential mechanism responsible for obesity associated colorectal cancer. Obes Res Open J. 2015;1(1):10-5.

35. Tilg H, Moschen AR. Adipocytokines: mediators linking adipose tissue, inflammation and immunity. Nat Rev Immunol. 2006;6(10):772-83.

36. Fischer-Posovszky P, Wabitsch M, Hochberg Z. Endocrinology of adipose tissue - an update. Horm Metab Res. 2007:39(5):314-21.

37. Oguma $K$, et al. Activated macrophages promote Wnt signalling through tumour necrosis factor-alpha in gastric tumour cells. EMBO J. 2008;27(12): 1671-81.

38. Wang $\mathrm{Y}$, et al. Adiponectin modulates the glycogen synthase kinase-3beta/ beta-catenin signaling pathway and attenuates mammary tumorigenesis of MDA-MB-231 cells in nude mice. Cancer Res. 2006;66(23):11462-70.

39. Renehan AG, Roberts DL, Dive C. Obesity and cancer: pathophysiological and biological mechanisms. Arch Physiol Biochem. 2008;114(1):71-83.

\section{Publisher's Note}

Springer Nature remains neutral with regard to jurisdictional claims in published maps and institutional affiliations.

Ready to submit your research? Choose BMC and benefit from:

- fast, convenient online submission

- thorough peer review by experienced researchers in your field

- rapid publication on acceptance

- support for research data, including large and complex data types

- gold Open Access which fosters wider collaboration and increased citations

- maximum visibility for your research: over $100 \mathrm{M}$ website views per year

At $\mathrm{BMC}$, research is always in progress.

Learn more biomedcentral.com/submissions 